\title{
Raised levels of exhaled carbon monoxide are associated with an increased expression of heme oxygenase- 1 in airway macrophages in asthma: a new marker of oxidative stress
}

\author{
Ildikó Horváth, Louise E Donnelly, András Kiss, Paolo Paredi, Sergei A Kharitonov,
} Peter J Barnes

\begin{abstract}
Background-Chronic inflammatory diseases are associated with an increased production of oxidants. Induction of a stress protein, heme oxygenase (HO) HO-1, is a cytoprotective mechanism against oxidative cellular injury. HO-1 catabolises heme to bilirubin, free iron, and carbon monoxide (CO).

Methods-Exhaled CO and sputum bilirubin levels were measured and HO-1 protein expression in airway macrophages was determined by Western blotting in asthmatic patients as levels of oxidants are raised in asthma and may induce HO-1.

Results-Exhaled CO was significantly increased in 37 non-steroid treated asthmatic patients compared with 37 healthy subjects (5.8 (95\% CI 5.20 to 6.39) ppm vs 2.9 ( 2.51 to 3.28$) \mathrm{ppm}$; $\mathrm{p}<0.0001$ ) but was similar to normal in 25 patients who received corticosteroids $(3.3$ (95\% CI 2.92 to 3.67) ppm; $p>0.05$ ). In non-treated asthmatic patients more HO-1 protein was expressed in airway macrophages than in normal subjects. Bilirubin levels in induced sputum were also higher than in normal subjects. Inhalation of hemin, a substrate for HO, significantly increased exhaled CO from 3.8 (95\% CI 2.80 to 4.87 ) ppm to 6.7 (95\% CI 4.95 to $8.38 \mathrm{CI}) \mathrm{ppm}$ $(p<0.05)$ with a concomitant decrease in exhaled nitric oxide levels, suggesting an interaction between the two systems.

Conclusions-Increased exhaled CO levels and HO-1 expression may reflect induction of HO-1 which may be inhibited by steroids. Measurement of exhaled CO, an index of HO activity in non-smoking subjects, may therefore be clinically useful in the detection and management of asthma and possibly other chronic inflammatory lung disorders.

(Thorax 1998;53:668-672)
\end{abstract}

Keywords: heme oxygenase-1; asthma; exhaled carbon monoxide; inflammation

Oxidative stress has been implicated in the pathogenesis of many diseases including atherosclerosis, carcinogenesis, and chronic inflammatory disorders such as asthma, chronic obstructive pulmonary disease (COPD), rheumatoid arthritis, and psoriasis. ${ }^{1-5}$
In these chronic diseases reactive oxygen species (ROS) - including the superoxide anion, hydroxyl radicals, and hydrogen peroxide $\left(\mathrm{H}_{2} \mathrm{O}_{2}\right)$-are produced by activated immune and inflammatory cells. These mediators amplify and perpetuate the disease state by the oxidation of nucleic acids, proteins, and membrane lipids. ${ }^{6}$ Organisms have evolved both non-enzymatic and enzymatic antioxidant defence systems to detoxify these harmful oxidants. One of these defence mechanisms is the induction of a stress response protein, $\mathrm{HO}-1 .{ }^{6}{ }^{7}$ HO- 1 catalyses the initial and rate limiting step in the oxidative degradation of heme to bilirubin. The enzyme, utilising NADPH and molecular oxygen, cleaves a meso carbon of the heme molecule producing biliverdin, free iron, and $\mathrm{CO}^{8}$ Biliverdin is then converted to bilirubin by bilirubin reductase. Bilirubin itself is an antioxidant and $\mathrm{CO}$ has several biological activities including stimulation of guanylate cyclase. ${ }^{9} \mathrm{HO}-1$ induction therefore has been suggested as a protection against oxidant mediated cellular injury. ${ }^{10}$ Several mediators which are also released during chronic inflammation including cytokines, ROS, and nitric oxide (NO) are able to induce $\mathrm{HO}-1$ expression under experimental conditions. ${ }^{6} 7$ Despite these lines of evidence implicating a potential induction and role for $\mathrm{HO}-1$ in human diseases associated with oxidative stress, its expression and activity have not been determined in these conditions.

Asthma is a chronic inflammatory disease of the airways with increased ROS and nitric oxide (NO) production and raised levels of several inflammatory mediators in the airways, all of which may be potential inducers of $\mathrm{HO}-1$ expression. ${ }^{311}$

Increased levels of exhaled $\mathrm{CO}$ have recently been demonstrated in patients with asthma not treated with corticosteroids, and changes in $\mathrm{CO}$ concentration were significantly related to those in the eosinophil cell counts in sputum. ${ }^{12}$ We postulated therefore that HO-1 enzyme would be expressed more intensively and levels of its end products, $\mathrm{CO}$ and bilirubin, would be higher in the airways of asthmatic patients than in normal subjects. Glucocorticosteroids, which control inflammation in asthmatic airways, may inhibit the expression of $\mathrm{HO}-1$ and therefore may result in a decreased concentration of exhaled CO. We have determined the levels of HO-1 protein expression in macrophages obtained from induced sputum, measured levels of 

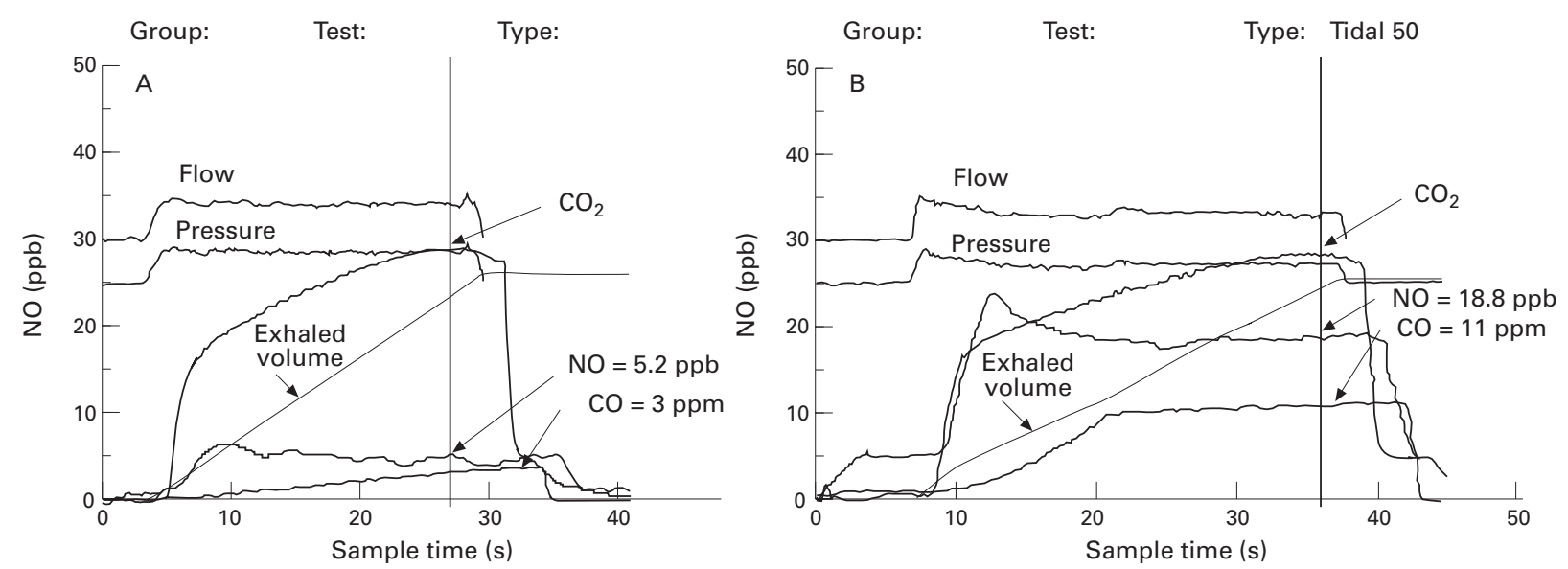

Figure 1 Representative original traces of expired $C O$ and NO in (A) a normal subject and (B) an asthmatic patient.

bilirubin in sputum supernatant, and $\mathrm{CO}$ in exhaled air in normal and asthmatic subjects. As active and passive smoking influences levels of exhaled $\mathrm{CO}$ and may interfere with its endogenous production, we therefore recruited only non-smoking individuals and tested nonsmoking status by determining the levels of nicotine and its metabolites in urine.

\section{Methods}

SUBJECTS

Non-smoking subjects were recruited from volunteers taking part in other studies and from outpatients at the Royal Brompton Hospital. None of the controls (20 men and 17 women of mean age 33 (95\% CI 27.5 to 38.6) years) had a history of respiratory or cardiovascular disease or was receiving long term medication. Asthmatic patients were atopic and had documented reversible airway obstruction and airway hyperresponsiveness (methacholine $\mathrm{PC}_{20}<8 \mathrm{mg} / \mathrm{ml}$ ). They were stable for at least two weeks before study. One group received either no regular treatment or inhaled $\beta_{2}$ agonists alone $(20$ men and 17 women of mean age 32 (95\% CI 26.7 to 37.3 ) years) and the others received regular inhaled steroids (beclomethasone dipropionate or budenoside 400-1600 $\mu \mathrm{g}$ daily; 11 men and 14 women of mean age 36 (95\% CI 30.3 to 41.5 ) years). Spirometric tests showed a mean forced expiratory volume in one second $\left(\mathrm{FEV}_{1}\right)$ of 94 (95\% CI 87.9 to 100.1$) \%$ predicted and 77 (95\% CI 70.0 to $83.9 \mathrm{CI}$ ) \% predicted for the non-steroid treated and the steroid-treated groups, respectively. Subjects were tested by NicCheck I (DynaGen Inc, Cambridge, Massachusetts, USA), which determines the levels of nicotine and its metabolites, to ensure nonsmoking status and active and passive smokers (smoke exposure for more than 0.5 hour/day) were excluded from the study. The study was approved by the ethics committee of the Royal Brompton Hospital and informed consent was obtained from all subjects.

EXHALED CO

Exhaled $\mathrm{CO}$ was measured by a modified analyser (EC50-MICRO Smokerlyzer CO monitor, Bedfont Scientific Ltd, UK) sensitive to $\mathrm{CO}$ from 0 to 500 parts per million (ppm, by volume), adapted for online recording of $\mathrm{CO}$ concentration and integrated with a chemiluminescence analyser (LR 2000, Logan Research, Rochester, UK) to control exhalation parameters. The subjects exhaled slowly from functional vital capacity with a constant flow (5-6 l/min) against resistance $(3(0.4) \mathrm{mm} \mathrm{Hg})$ over $20-30$ seconds into the analyser. Two successive recordings were made and mean values were used in all calculations. Ambient CO levels were recorded before each breath. Exhaled NO was measured as described previously. ${ }^{13}$

To show that baseline levels of $\mathrm{CO}$ can be increased by influencing heme oxygenase (HO) activity, six subjects inhaled solution of an active substrate analogue, hemin (Sigma Chemical Co, Poole, UK) (2 ml of $\left.10^{-4} \mathrm{M}\right)$. Levels of exhaled $\mathrm{CO}$ and $\mathrm{NO}$ were measured for four hours since changes in CO levels may interact with NO production.

INDUCED SPUTUM

HO-1 protein expression was measured in airway macrophages obtained from induced sputum samples. Sputum was induced from nine non-steroid treated asthmatic and seven normal subjects. Subjects inhaled $3.5 \%$ saline solution at room temperature nebulised by an ultrasonic nebuliser (DeVilbiss 99, De Vilbiss, Heston, UK) for 15 minutes. Subjects were encouraged to cough deeply after five minutes and at five minute intervals thereafter. Sputum was coughed into polypropylene containers and were kept at $4^{\circ} \mathrm{C}$ for not more than two hours before further processing. The volume of the samples was recorded. The sample was diluted with phosphate buffered saline containing $10 \mathrm{mmol} / 1$ dithiotreitol and gently vortexed at room temperature. The samples were then centrifuged at $400 \mathrm{~g}$ for 10 minutes and the cell pellet thus formed was resuspended. The supernatant was stored at $-70^{\circ} \mathrm{C}$ for subsequent assay for bilirubin concentration. The cell pellet was washed twice with Hank's balanced salt solution (HBSS) without $\mathrm{Ca}^{2+}$ and $\mathrm{Mg}^{2+}$. The cells were stained with Kimura stain and macrophages counted using a haemocytometer. The macrophages were resuspended in RPMI1640 media containing $10 \%(\mathrm{v} / \mathrm{v})$ fetal calf serum, $2 \mathrm{mM}$ glutamine $100 \mu \mathrm{g} / \mathrm{ml}$ penicillin, and $100 \mathrm{u} / \mathrm{ml}$ streptomycin. Macrophages were 


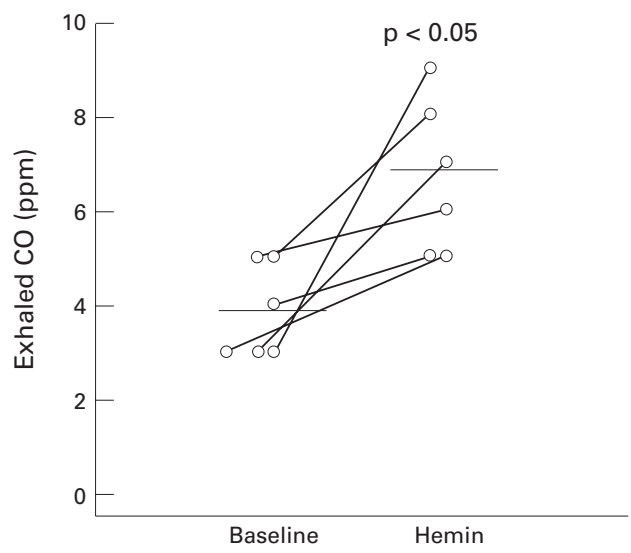

Figure 2 Effect of hemin on exhaled CO levels in normal subjects $(n=6)$.

seeded at a density of $1 \times 10^{6}$ cells/well on a six well plate and allowed to adhere for 90 minutes in a humidified incubator at $37^{\circ} \mathrm{C}$ and $95 \%$ $(\mathrm{v} / \mathrm{v})$ air, $5 \%(\mathrm{v} / \mathrm{v}) \mathrm{CO}_{2}$, after which the non-adherent cells were removed by washing with HBSS. The adherent cells were scraped off the plate and identified as macrophages by staining with Kimura stain. This process resulted in the recovery of approximately $50 \%$ of the plated cells and there were no differences in the recovery between each group of subjects. The resulting cell pellet was stored at $-20^{\circ} \mathrm{C}$ until required.

BILIRUBIN ASSAY

The total bilirubin concentration in induced sputum was measured automatically by a time endpoint diazo method (Sinchron CX Systems, CX7 Delta Analyzer, Beckman Institute, UK) in the Department of Biochemistry, Royal Brompton Hospital.

HO-1 PROTEIN EXPRESSION

The gel system we use will not allow for all the samples to be run on the same gel, therefore we have used a blot that is representative of three separate gels. The HO-1 antibody used here is available commercially and has no cross reactivity with $\mathrm{HO}-2$. The cell pellets were homogenised in $50 \mathrm{mM}$ Tris/ $\mathrm{HCl} \mathrm{pH} 7.4$ containing $0.25 \mathrm{mM}$ EDTA, $0.5 \mathrm{mM}$ PMSF, 5 $\mu \mathrm{g} / \mathrm{ml}$ antipain, $5 \mu \mathrm{g} / \mathrm{ml}$ leupeptin, and $5 \mu \mathrm{g} / \mathrm{ml}$ benzamidine. Protein was determined using the BIORAD protein assay. The proteins were solubilised by boiling in SDS-PAGE sample buffer $(0.0625 \mathrm{mM}$ Tris/ $\mathrm{HCl}$ pH 6.8 containing $10 \% \mathrm{v} / \mathrm{v}$ glycerol, $1 \% \mathrm{w} / \mathrm{v}$ SDS, $1 \% \mathrm{w} / \mathrm{v}$ $\beta$-mercaptoethanol, and $0.01 \% \mathrm{w} / \mathrm{v}$ bromophenol blue). The proteins (10 $\mu$ g per lane) were resolved by electrophoresis in $12 \%$ SDS-

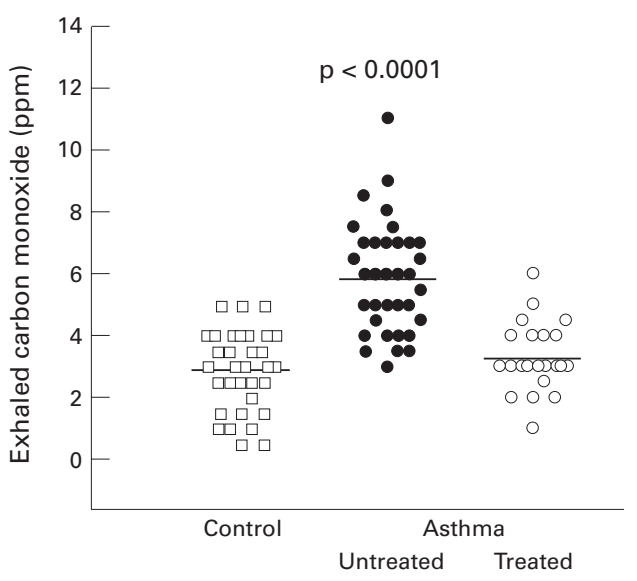

Figure 3 Exhaled CO concentrations in normal subjects $(n=37)$, asthmatic patients not on inhaled steroids $(n=$ $37)$, and asthmatic patients on inhaled steroids $(n=25)$.

polyacrylamide gels and transferred to nitrocellulose membranes. Equal protein loading was determined by staining the blot with $0.1 \%$ $(\mathrm{w} / \mathrm{v})$ Porcean $\mathrm{S}$ in $5 \%(\mathrm{v} / \mathrm{v})$ acetic acid. The nitrocellulose was blocked overnight at $4^{\circ} \mathrm{C}$ in $10 \% \mathrm{w} / \mathrm{v}$ dried milk protein in PBS containing $0.05 \% \mathrm{v} / \mathrm{v}$ Tween-20. The blots were washed in PBS containing $0.05 \% \mathrm{v} / \mathrm{v}$ Tween-20 and incubated for one hour in the presence of rabbit-anti-heme oxygenase-1 antibody (1:7500) (Affiniti Prod. Ltd, Exeter, UK). The blots were washed extensively and then incubated for one hour with anti-rabbit IgG conjugated to horse radish peroxidase (1:4000). The blots were washed extensively again and the bands were visualised using ECL (Amersham, Amersham Place, UK).

ANALYSIS OF DATA

The $95 \%$ confidence intervals (CI) were calculated with standard algorithms. Comparisons between groups were made by the Student's $t$ test. Significance was defined as $\mathrm{p}<0.05$.

\section{Results}

EXHALED CO

Exhaled CO was detectable in all subjects (fig 1). Measurements in normal subjects $(n=33)$ were reproducible, the variation between readings on separate days being $5.3 \%$. Ambient air concentrations of $\mathrm{CO}(0-2 \mathrm{ppm})$ did not affect exhaled CO readings as there was no difference in $\mathrm{CO}$ levels after inhalation of certified $\mathrm{CO}$ free air (BOC, UK) compared with room air in four normal and five asthmatic subjects. The exhaled CO concentration was 2.9 (95\% CI 2.51 to 3.28$) \mathrm{ppm}$ in normal non-smoking subjects.

Table 1 Characteristics of subjects

\begin{tabular}{lllllll}
\hline Subjects & Sex $(F / M)$ & Age $(y)$ & Atopy & $\begin{array}{l}F E V_{1}(\% \\
\text { predicted })\end{array}$ & $\begin{array}{l}P C_{20} F E V_{1} \\
(m g / m l)\end{array}$ & $\begin{array}{l}\text { Inhaled corticosteroids } \\
(\mu g / \text { day })\end{array}$ \\
\hline $\begin{array}{l}\text { Control }(\mathrm{n}=37) \\
\text { Asthma }\end{array}$ & $17 / 20$ & $33(28-39)$ & 0 & $101(5)$ & $>16$ & - \\
$\quad \begin{array}{l}\text { No steroids }(\mathrm{n}=37) \\
\quad \text { Steroids }(\mathrm{n}=25)\end{array}$ & $17 / 20$ & $32(27-37)$ & 31 & $95(5)$ & $0.44(0.09)^{\star}$ & - \\
\hline
\end{tabular}

${ }^{\star}$ Geometric mean (SE); data shown as mean (SE) except for $\mathrm{PC}_{20}$.

Atopy $=$ positive immediate skin test to one or more aero-allergens; $\mathrm{FEV}_{1}=$ forced expiratory volume in one second; $\mathrm{PC} \mathrm{C}_{20}=$ provocative concentration of methacholine producing a $20 \%$ fall in $\mathrm{FEV}_{1}$. 


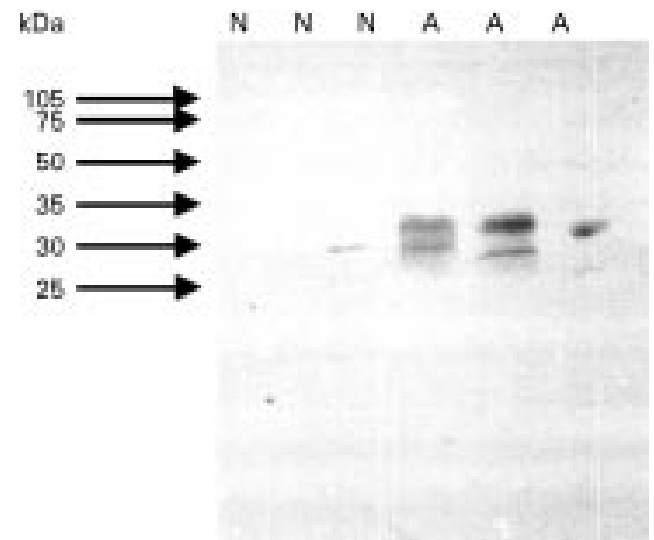

Figure 4 Western blot analysis of $\mathrm{HO}-1$ in airway macrophage lysate (10 $\mu \mathrm{g}$ protein/lane); $N=$ samples from control healthy subjects; $A=$ samples from asthmatic patients.

Hemin inhalation significantly increased expiratory CO concentrations from 3.8 (95\% CI 2.8 to 4.87$) \mathrm{ppm}$ to 6.7 (95\% CI 4.95 to 8.38) ppm $(\mathrm{p}<0.05)$ with a concomitant decrease in exhaled NO concentrations from $5.4(95 \%$ CI 4.22 to 6.57$) \mathrm{ppb}$ to $3.2(95 \% \mathrm{CI}$ 1.84 to 4.60$) \mathrm{ppb}(\mathrm{p}<0.01)$ in six normal subjects (fig 2).

In asthmatic patients not receiving corticosteroids the CO levels were significantly higher than normal (5.8 (95\% CI 5.20 to 6.39) ppm; $\mathrm{p}<0.0001)$ whereas in asthmatic patients receiving inhaled corticosteroids exhaled $\mathrm{CO}$ was significantly reduced compared with values in untreated subjects and did not differ significantly from those of normal subjects 3.3 (95\% CI 2.92 to 3.67) ppm (fig 3).

SPUTUM BILIRUBIN LEVELS

Bilirubin was detectable in each of the sputum samples and its concentration was increased in nine patients with asthma compared with seven normal subjects (5.8 (95\% CI 4.61 to 6.89 ) $\mu \mathrm{M}$ vs 3.6 (95\% CI 2.82 to 4.40$) \mu \mathrm{M} ; \mathrm{p}<0.05)$.

HO-1 EXPRESSION

Western blot analysis showed that $\mathrm{HO}-1$ is expressed at a higher level in airway macrophages obtained from induced sputum of asthmatic patients $(n=6)$ compared with normal subjects $(n=6)($ fig 4$)$.

\section{Discussion}

This study shows that raised levels of $\mathrm{CO}$ in exhaled air of asthmatic subjects are associated with increased expression of HO-1 in induced sputum macrophages and increased levels of bilirubin in sputum compared with healthy subjects, and that exhaled CO may be modified by corticosteroid treatment. Inhalation of hemin significantly increased the levels of exhaled $\mathrm{CO}$ in normal and asthmatic subjects. Detection of exhaled CO as an index of heme oxygenase activity may therefore reflect oxidative stress and could be a simple non-invasive tool for monitoring airway inflammation.

These results confirm the early observation ${ }^{12}$ that exhaled CO levels are raised in asthma, reduced by inhaled corticosteroids, and that ambient air CO concentrations (at levels of 0-2 ppm) do not affect exhaled CO.
Exhaled CO and sputum bilirubin concentrations were significantly higher than normal in asthmatic patients who were not receiving inhaled steroids. In asthmatic airways induction of HO-1 may lead to the high exhaled CO concentrations observed in the present study. Increased HO-1 protein expression may be due to the induction of the enzyme by inflammatory mediators present in the asthmatic airways. Many cytokines and oxidants involved in asthmatic inflammation-including interleukins, tumour necrosis factor $\alpha$, interferon- $\gamma$, $\mathrm{NO}$, and $\mathrm{H}_{2} \mathrm{O}_{2}$ - are able to induce $\mathrm{HO}-1$ expression in cell lines and tissues under experimental conditions. ${ }^{67}$

This study, however, is the first to show an increase in HO-1 expression in vivo in patients. The normal exhaled $\mathrm{CO}$ levels in steroid treated patients suggest that inhaled steroids may inhibit HO-1 expression in the airways.

The cellular source of $\mathrm{CO}$ in asthmatic patients is not known although our present study would implicate airway macrophages. These cells are known to be activated in asthma and to produce superoxide anions after activation, which may explain the increased HO-1 expression in these cells. ${ }^{3}$ HO-1 may be induced in various other superficial cells in the respiratory tract including epithelial cells and infiltrating inflammatory cells. ${ }^{14}$ The induction of HO-1 has been implicated as an antioxidant defence mechanism. By degrading heme, a pro-oxidant contained in a multiplicity of intracellular proteins, and by generating bilirubin, an antioxidant which can scavenge hydroxyl radicals in vitro as efficiently as $\alpha$-tocopherol, induction of $\mathrm{HO}-1$ may provide antioxidant protection. ${ }^{9}{ }^{15} \mathrm{CO}$, a by-product of $\mathrm{HO}$ activity, activates guanylate cyclase and it is a putative neurotransmitter. ${ }^{16}$ However, when produced in high local concentrations by inducible $\mathrm{HO}, \mathrm{CO}$ may have pro-inflammatory effects since it is also a potent vasodilator and may increase plasma exudation from airway vessels. ${ }^{17}$ Free iron, another end product of HO-1, can act as a catalyst in the formation of ROS and through this mechanism it may have inflammatory effects; however, it also induces ferritin expression which may serve to restrict iron from participation in the Fenton reaction, thereby reducing the oxidant burden of the cell. ${ }^{10}{ }^{18}$

The induction of HO-1 has been shown to participate in resolution of acute inflammation under experimental conditions and it has been suggested that it may play a cytoprotective role in heme and oxidant induced cellular injuries. ${ }^{19}$ These observations raise the possibility that overexpression of HO-1 may be beneficial in the treatment of chronic inflammatory diseases. Measurement of exhaled CO, an index of HO activity, may be a simple method of detecting and monitoring cytokine mediated inflammation in the respiratory tract and of assessing anti-inflammatory treatments. As CO measurement is simple and non-invasive, it is repeatable and is possibly useful in children and patients with severe disease who may not tolerate more invasive investigation. Further studies are needed, however, to relate expired 
$\mathrm{CO}$ and sputum bilirubin levels to the extent of inflammation and to explore this approach in other inflammatory lung diseases. We speculate that there may be a sequential induction of enzymes that include cyclooxygenase- 2 and inducible nitric oxide synthase, followed by increased expression of enzymes with antiinflammatory effects, including HO-1. The close inverse relationship between the regulation of $\mathrm{CO}$ and $\mathrm{NO}$ production is reflected by the reduced exhaled NO concentrations after increasing exhaled CO levels.

In conclusion, the findings of this study implicate a direct involvement of HO-1 in asthmatic inflammation. The presence of HO-1 in the airway macrophages, a cell type closely associated with chronic inflammation, would support the concept of this enzyme as a modulator of the chronic inflammatory response. Measurement of exhaled CO may be clinically useful for monitoring oxidant mediated pulmonary diseases.

IH was supported by the European Respiratory Society and the Hungarian National Scientific Research Foundation (OTKAF017050), LED by the National Asthma Campaign (UK), SAK by the British Lung Foundation, and PP by the University of Milan.

1 Rahman I, Morrison D, Donaldson K, et al. Systemic oxidative stress in asthma, COPD, and smokers. Am $\mathcal{F}$ Respir Crit Care Med 1996;154:1055-60.

2 Repine JE, Bast A, Lankhorst I. Oxidative stress in chronic obstructive pulmonary disease. Oxidative Stress Study Group. Am f Respir Crit Care Med 1997;156:341-57.

3 Barnes PJ. Reactive oxygen species and airway inflammation. Free Radic Biol Med 1990;9:235-43.
4 Rice EC, Burdon R. Free radical-lipid interactions and their pathological consequences. Prog Lipid Res 1993;32:71-110.

5 Halliwell B. The role of oxygen radicals in human disease, with particular reference to the vascular system. Haemostasis 1993;23(Suppl 1):118-26.

6 Choi AM, Alam J. Heme oxygenase-1: function, regulation, and implication of a novel stress-inducible protein in oxidant-induced lung injury. Am f Respir Cell Mol Biol 1996;15:9-19.

7 Camhi SL, Lee P, Choi AM. The oxidative stress response. New Horiz 1995;3:170-82.

8 Tenhunen R, Marver HS, Schmid R. The enzymatic conversion of heme to bilirubin by microsomal heme oxygenase. Proc Natl Acad Sci USA 1968;61:748-55.

9 Stocker R, Yamamoto Y, McDonagh AF, et al. Bilirubin is an antioxidant of possible physiological importance. Science 1987;235:1043-6.

10 Vogt BA, Alam J, Croatt AJ, et al. Acquired resistance to acute oxidative stress. Possible role of heme oxygenase and ferritin. Lab Invest 1995;72:474-83.

11 Kharitonov SA, Yates DH, Robbins RA, et al. Increased nitric oxide in exhaled air of asthmatic patients. Lancet 1994;343:133-5.

12 Zayasu K, Sekizawa K, Okinaga S, et al. Increased carbon monoxide in exhaled air of asthmatic patients. Am f Respir Crit Care Med 1997;156:1140-3.

13 Kharitonov, SA, Chung, FK, Evans, et al. The elevated level of exhaled nitric oxide in asthmatic patients is mainly derived from the lower respiratory tract. Am $\mathcal{F}$ Respir Crit Care Med 1996;153:1773-80.

14 Lee PJ, Alam J, Sylvester SL, et al. Regulation of heme oxygenase-1 expression in vivo and in vitro in hyperoxic lung injury. Am f Respir Cell Mol Biol 1996;14:556-68.

15 Stocker R. Induction of haem oxygenase as a defence against oxidative stress. Free Radic Res Commun 1990;9: against $101-12$.

16 Dawson TM, Snyder SH. Gases as biological messengers: nitric oxide and carbon monoxide in the brain. $\mathcal{F}$ Neurosci 1994;14:5147-59

17 Morita T, Perrella MA, Lee ME, et al. Smooth muscle cellderived carbon monoxide is a regulator of vascular cGMP. Proc Natl Acad Sci USA 1995;92:1475-9.

18 Morris CJ, Earl JR, Trenam CW, et al. Reactive oxygen species and iron: a dangerous partnership in inflammation. Int f Biochem Cell Biol 1995;27:109-22.

19 Willis D, Moore AR, Frederick R, et al. Heme oxygenase: a novel target for the modulation of the inflammatory response. Nature Med 1996;2:87-90. 